CZU: 821.135.1-1(478).09+398.21

https://doi.org/10.52505/lecturi.2021.05.03

\title{
GEORGE MENIUC VS TATIANA GĂLUŞCĂ: REGĂSIREA SPIRITUALĂ PRIN FOLCLOR
}

\author{
Tatiana BUTNARU \\ Institutul de Filologie Română „Bogdan Petriceicu-Hasdeu”, Chișinău
}

Rezumat. În articolul de faşă este dezvăluită colaborarea lui G. Meniuc cu Tatiana Găluşcă pe tărâmul cuvântului artistic, ceea ce l-a determinat să pătrundă mai temeinic în universul spiritualităţii populare, să ajungă la ,o sinteză dintre geniul anonim şi valoarea individuală”, oferindu-i noi posibilităţi de resurecţie în modulaţiile codului estetic al poporului, a eticii sale multiseculare de viaţă. Odată ce „lumea asta e o transpunere în mit, vis de care are nevoie omul", sugestie vehiculată de T. Găluşcă, G. Meniuc a reuşit să sintetizeze nişte imagini poetice, ce se redimensionează în conformitate cu straturile arhaice ale mentalităţii populare, acestea fiind dirijate de o logică mitică interioară, de resorturi şi stări sufleteşti deosebite. Reprezentările populare şi toposurile folclorice prefigurează în viziunea lui G. Meniuc un mediu tradiţional, omniprezent în mai multe versuri, determină aprofundarea anumitor aspecte ale realităţii artistice curente. Dialogul G. Meniuc vs T. Găluşcă, colaborarea lor sufletească pe tărâmul creației artistice a devenit un frumos exemplu de comunicare spirituală, ,o creangă de aur” menită să dăinuie dincolo de hotarele existenţei terestre.

Cuvinte-cheie: Toposuri folclorice, sugestie mitică, dialog spiritual, orientare estetică, element convenţional, mentalitate populară, analogie metaforică.

Abstract. This article reveals George Meniuc's collaboration with Tatiana Găluşcă on the realm of the artistic word, which has led them to penetrate more deeply into the universe of folk spirituality, to reach "a synthesis of anonymous genius and individual value" by giving them new possibilities of resurrection in the modulation of the aesthetic code of the people, of their ethics, multiseculate of life. Once "this world is a transposition into the myth, a dream that man needs", a suggestion conveyed by T. Găluşcă, G. Meniuc managed to synthesize some poetic images, which are resized according to the archaic layers of the popular mentality, these being driven by an inner mythical logic, springs and special states of mind. Folk performances and folkloric tops predict a traditionally omnipresent environment in several writings, which determines the deepening of some aspects of the current artistic reality. The dialogue between G. Meniuc and T. Găluşcăa, their soul collaboration on the realm of artistic creation has become a beautiful example of spiritual communication, ,a golden branch" meant to survive beyond the boundaries of terrestrial existence.

Keywords: Folkloric topos, mythical suggestion, spiritual dialogue, aesthetic orientation, conventional element, popular mentality, metaphorical analogy. 
Afirmat în literatură la o răscruce a istoriei, ,printre florile de pârloagă" a Basarabiei, G. Meniuc avea să aprofundeze destinul unei generaţii de scriitori, pentru care folclorul devenise un factor primordial în afirmarea sa artistică, în procesul de modelare a individualităţii scriitoriceşti. Mărturisirea lui Gr. Vieru „Într-un fel generaţia noastră este folclorică”, iar „creaţia populară orală a exercitat o influenţă covârşitoare asupra noastră" (Saca, 1976, p. 207), constituie profesiunea de credinţă a unei pleiade de oameni de creaţie, pentru care folclorul semnifică un tezaur spiritual, este o resurecţie în modulaţiile codului estetic al poporului, a eticii sale multiseculare de viaţă. Colaborarea cu folclorista T. Găluşcă 1-a determinat sa pătrundă mai temeinic în universul spiritualităţii autohtone, sa ajungă la ,o sinteză dintre geniul anonim şi valoarea individuală"(Teodorescu, 1983, p. 70), creând „o poezie de o certă vibraţie originală, ale cărei rădăcini şi a cărei forţă de audienţă se explică prin apartenenţa la universul de gândire şi simţire al poporului" (Teodorescu, 1983, p. 70). Făcând abstracţie de vicisitudinile timpului, în care a activat G. Meniuc, el a revenit la ,uneltele sale”, anume, datorită surselor de inspiraţie folclorică, ceea ce i-a oferit noi posibilităţ̧i de afirmare scriitoricească, de purificare şi înnobilare spirituală, pentru aprofundarea unui vast bagaj intelectual, cu orientare spre valorile culturii europene. Voluptatea simţirii folclorice, stihia datinilor, credinţelor populare s-au infiltrat organic în opera sa, a constituit un imbold creator şi, în acelaşi timp, o sursă sigură de reconfortare spirituală. Or, aşa cum se destăinuia G. Meniuc, prietenei sale din tinereţe T. Găluşcă: „,...am avut norocul să cunosc prin tine bogăţiile spirituale ale poporului, şi multe lucrări ce leam scris pe vremuri au fost influenţate de limba folclorului. Elementul convenţional de care este plină arta populară mi-a folosit enorm" (Meniuc, 2010, p. 109). Poezia şi folclorul s-au contopit în intuiţia artistică a lui G. Meniuc şi s-au manifestat spre o cunoaştere mai profundă a tainelor existenţiale ale universului, 1-au orientat spre o înaltă cultură estetică, strâns legată de tradiţie, dar orientată spre viziuni monumentale, spre o sintetizare a valorilor spirituale ale omenirii, întrucât după propria lui mărturisire, „fără folclor nu există o artă mare” (Meniuc, 2010, p. 98).

Odată ce „lumea asta e o transpunere în mit, vis de care are nevoie omul” (Meniuc, 2010, p. 181), sugestie vehiculată la rândul ei de T. Găluşcă, ea îşi va găsi expresie prin nişte eresuri populare cu,,solomonari..., urmele străvechilor magicieni care prin puritate, forţă spirituală şi puterea cuvântului stăpâneau natura,... alungau norii..., îşi măsurau puterile prin strigături, vorbe meşteşugite" (2010, p. 181). Metaforic vorbind, din această „căruţă de folclor” (2010, p. 111), culeasă şi oferită cu discreţie de T. Găluşcă, poetul a reuşit să sintetizeze nişte imagini artistice, ce se vor redimensiona în conformitate cu straturile arhaice ale mentalităţii populare, acestea fiind dirijate de o logică mitică interioară, de nişte resorturi şi stări sufleteşti deosebite. Opinia vehiculată de T. Găluşcă este expusă în directă legătură cu 
reprezentările populare şi toposurile folclorice din tradiţia autohtonă, care luate toate împreună vor prefigura un mediu tradiţional, omniprezent în mai multe scrieri ale lui G. Meniuc, ceea ce demonstrează „variabilitatea materiei în timp şi spaţiu”, determină aprofundarea anumitor aspecte ale realităţii curente, cu deschidere spre multiple dimensiuni ontologice şi existenţiale. Toposurile folclorice, omniprezente în viziunea artistică a lui G. Meniuc, se manifestă într-o orientare conceptuală, etică, estetică, gnoseologică şi capătă un caracter arhetipal, aşa cum vedem din lectura mai multor scrieri.

Calea pe care o parcurge eroul liric a lui G. Meniuc de la rezonanţele tragice ale „naufragiului” sufletesc până la solitudinea mioritică din Balada şarpelui de casă îi permite să valorifice noi zone ideatice, să dezvăluie o realitate conceptual-artistică de factură baladescă, cu deschidere spre rolul protector al unor simboluri şi arhetipuri mitice. Semnificaţia magică a acestora deţine o funcţie de mediere a situaţiilor dramatice, se condensează în efluviul unui lirism reconfortant.

„Nu uitaţi şarpele de sub talpa stânei.

El veghează asupra turmei, în luncă.

Şi cârligul, bâta cioplită frumos.

Cu cap de balaur, la capăt întors."

\section{(G. Meniuc, Balada şarpelui de casă)}

Metaforele şi imaginile artistice au deschidere către un spaţiu de valori circumscrise într-o lumină iniţiatică, fiind orientate spre estimarea unor sensuri primordiale, cu un substrat mitologic străvechi. Aşadar, ,şarpele casei, după sugestia unor folclorişti, are funcţia de spirit protector al spaţiului domestic, de garant al norocului şi viitorului casei” (Coman, 1996, p. 100), iar „dacă pleacă şarpele sau e omorât, precizează în altă parte şi T. Găluşcă, moare turma” (Meniuc, 2010, p. 189).

Văzut în dimensiunile descriptive ale imaginaţiei populare, aşa cum şi-a găsit expresie în unele texte folclorice culese şi înregistrate de T. Găluşcă, toposul şarpelui poartă un caracter sincretic, el devine expresia unui concept existenţial, este „un model simbolic în concepţiile şi reprezentările arhaice despre univers”, „un arhetip al ambiguităţii specifice tuturor simbolurilor fundamentale şi o ilustrare vie a anulării sau contopirii contrariilor în gândirea arhaică" (Evseev, 1999, p. 180). Epizoadele descrise într-o baladă din volumul semnat de T. Găluşcă, I. Nicola Folclor român din Basarabia, ediţie îngrijită de Gr. Botezatu şi T. Colac, se manifestă printr-o semnificaţie arhetipală şi relevă tendinţa de a contura o lume neordinară, contradictorie prin însăşi esenţa ei. Voinicul înghiţit sau sugrumat de şarpe, „Jumătate 1-o mâncat,/ Jumătate nu-1 mai poate,/ De cuţâte ascuţite,/ De curăle arămite" (Găluşcă, Nicola, 1999, p. 600), este împlinirea blestemului matern, iar prin analogie metaforică, se poate subînțelege fatalitatea existenţei umane, aflată 
sub puterea malefică a destinului. Soarta omului este prefigurată în şarpe, „fiecare om are şarpele său" (Ferber, 2001, p. 99), care în cele din urmă îi devoră existenţa. Resemnarea celui ,înghiţit de şarpe”, adică, aflat sub puterea nefastă a destinului, este de sorginte mioritică şi oferă noi orizonturi de înţelegere a lumii.

În poezia de Sub cer de G. Meniuc ,se despleteşte părul ca şerpii pe jos în furtună”, ca să se dizolve ,într-o emoţie universală”, iar „,crengile au febră ca şerpii-n asfinţit”. La un anumit moment, pare că întreg universul este invadat de şerpi, ca în cele din urmă, autorul să contureze o stare de coşmar existenţial.

„Tot pamântul e înnoptat de privirea lor,

Toată padurea e plină de şerpi.

Crengile se zbat, şoptesc, înţeapă şi râd ca şerpii

Şi părul e şarpe. Şi vântul e şarpe."

(Şerpii)

Critica literară întrevede în situaţia poetică descrisă o primejdie, un avertisment în legătură cu ,strecurarea nestăvilită şi periculoasă - prin lucruri - a Răului către Om” (Dolgan, 1974, p. 89). Receptarea artistică a acestui fenomen poate fi interpretată prin prisma mai multor puncte de vedere, care vor depăşi situaţia malefică prefigurată mai sus. Folcloriştii au încercat nu o singură dată să explice simbolismul şarpelui și să-1 încadreze în ,graniţele dintre materie şi spirit” (Evseev, 1999, p. 180), să-1 prezinte drept „o întruchipare a materiei primare, a pământului şi a apei, a amestecului dintre fenomenele naturii" (1999, p. 180). Mitologia şarpelui aprofundează o tematică complexă, găsindu-şi expresie într-o polaritate existenţială specifică, ne orientează spre nişte simboluri arhetipale apropiate de ,viziunea prin suflet a unui fenomen primar” (Bălăeţ, 1979, p. 35). În ultimă instanţă, toposul şarpelui relevă o realitate fabuloasă şi se impune prin necesitatea de a explica originea fenomenelor din natură, este imboldul spre sâmburele germinatoriu al universului. Ghidat de o experienţă expresionistă, G. Meniuc creează o zonă arhetipală, cu semnificaţii magice şi conotaţii mitice individualizatoare. Chiar şi elementele celeste capătă asociaţia unui şarpe, ca să se coaguleze printr-un joc al imaginaţiei simboliste, ceea ce-l determină pe autor să surprindă în acest arhetip mitic un mediator dintre cer şi pământ. Diferenţele de funcţionalitate şi iniţiere mitologică prevăd nişte mutaţii interioare, care se produc în sfera imaginarului artistic. De aceea, arhetipul şarpelui, în cele din urmă, capătă o încărcătură cosmică, el devine un simbol al unor dimensiuni ancestrale, care influenţează în permanenţă universul.

Balada şarpelui de casă de G. Meniuc este o scriere de inspiraţie mitică, unde „,cel nelumit, nescos la nuntă”, ,astrucat în câmpia largă”, este încadrat într-un ,salt ontologic" cauzat de un ritual magic. Are loc esenţializarea unor stări sufleteşti cu 
deschidere spre o problematică complexă, în conformitate cu un stereotip de credinţă populară binecunoscut. Poetul explorează înţelesurile filosofice ale mioriticului şi creează un sistem de simboluri tradiţionale, de o nuanţă specifică. Trecând peste aspectul de suprafaţă ale fiinţării lui pământeşti, drama existenţială a omului este plasată într-o lume selenară, superioară în esenţa ei. El este ocrotit de stihiile naturii, de „raza soarelui”, ce se identifică cu ochii şarpelui, aşa cum vedem întru-un text baladizat cules într-un context etnologic din regiunea Odessa:

„Colo-n vale într-o gradină

Se zăreşte o lumină, mumă,

Parcă-i raza soarelui, mai,

Dar nu-i raza soarelui,

Ci sunt ochii şarpelui, mumă."

(AF AŞM, 1968, f.43).

Recuperarea straturilor mitice are loc la G. Meniuc în funcție de caracterul arhetipal al imaginilor folclorice, oscilează de la viziunea mitică spre cea metafizică, spre o concepţie apropiată de miezul filosofiei populare. Privirea iniţiatică a şarpelui este „raza” prelinsă „din ochii lui înţelepţi” peste „,numele meu de mocan, pe care/ Soarele 1-a scris, ploile 1-au plâns". Sunt dezvăluite noi dimensiuni ale cunoaşterii umane, unde legătura dintre om şi univers se manifestă într-o procesualitate infinită. Viziunea modernă a versului, ţinuta intelectuală şi metafora elegantă aprofundează sensibilitatea unui temperament viguros, de o înaltă măiestrie artistică.

Expresie a unei vaste culturi scriitoriceşti, poezia lui G. Meniuc din anii '60-'80 asimilează deopotrivă atât elementele livreşti, cât şi cele din tezaurul spiritualităţii autohtone. Universul creaţiei sale se regăseşte în bogăţia de gândire şi simţire românească, înţelepciunea poporului, concepţia despre perenitatea mitului său existenţial. G. Meniuc îşi revigorează lirismul din perspectiva unei noi viziuni estetice, manifestată prin lărgirea orizonturilor ei spirituale şi general-umane, prin pregătirea unei conştiinţe artistice cu orientare despre universalizarea valorilor. El creează o poezie care pe măsura avansării sale în timp, prin democratizarea mijloacelor de investigaţie artistică, prin aprofundarea valorilor şi semnificaţiilor estetice, le substanţializează, le trece îndelung prin substraturile creativităţii populare. „Rădăcinile creaţiei lui G. Meniuc, scrie acad. M. Cimpoi, stau înfipte adânc în colinde şi balade, în reprezentările populare (adică în arhetipurile mitice), iar vârfurile ei le găsim înălţate semeţ ,în aerul distins al culturii universale...” (Cimpoi, 2004, p. 315).

Volumele de versuri Vremea lerului, Versuri alese, Florile dalbe, Toamna lui Orfeu confirmă justeţea aserţiunii de mai sus şi se prezintă drept nişte opere de sinteză, anunţă regăsirea de sine a lui Meniuc prin intermediul creaţiei populare. Vremea lerului este timpul mitic, încărcat de semnificaţia unui aer 
sacral, de o nostalgică îngândurare în faţa problemelor existenţiale. Este vremea meşterului din baladă, care încearcă să „reînnoade” firele întrerupte ale unui reflux poetic interior, ca să se menţină în dimensiunile spaţiului matrice ,între pământ şi cer, în uitare”, e „un spaţiu etern” al viselor şi speranţelor creatoare intuite ,prin confundarea în el însuşi şi prin întâlnirea meditaţiei şi contemplaţiei interioare" (Bomher, 1994, p. 1).

Florile dalbe este metafora ce determină sincronizarea lui G. Meniuc cu poezia universală, dar şi cu sugestia mitică din colindele strămoşeşti. Odată ce Florile răului de Baudelaire se impun printr-o antinomie mitică, ceea ce-l determină pe eroul liric să coboare din ,eternele grădini ale paradisului”, în purgatoriul suferinţelor umane, G. Meniuc, din contra, printr-o dezinvoltură romantică, încearcă să profileze nişte acorduri domoale ale melosului popular:

„Sculaţi, zorilor pe rouă,

Mânaţi oile împroor.

Sculaţi păsări măţăţele,

Ciripiţi pe crăcurele,

Sculaţi, ciute şi cerboane,

Iarba-i otova-n poiană..."

\section{(Colind de băiat)}

Toamna lui Orfeu continuă experienţa artistică din Florile dalbe, indicând cu mai multă pregnanţă revigorarea spiritului poetic, relevă calea de suprapunere a surselor de inspiraţie mitică cu resorturile poeticii moderne. Simbolul mitic al creatorului este recuperat dintr-o perspectivă insolită, el este artistul marcat de povara propriului destin, predispus sacrificiului prin creaţie. Mitul lui Orfeu devine o parte integrantă din concepţia despre lume a scriitorului, un imbold creator pentru realizarea unor scrieri unde „,noţiunile tradiţional-modern, împrumutinterpretare originală vor fi subordonate noii sinteze ca fapt artistic de neconfundat" (Cesereanu,1966, p. 495).

Fascinaţia mitului orfic din creaţia lui G. Meniuc este opus determinismului curent al vieţii materiale, el este invocat de scriitor ,pentru a spori expresivitatea propriilor idei, ca Blaga cu Meşterul Manole, Camus cu Sifif sau Freud cu Oedip” (Wald, 1992, p. 7). G. Meniuc problematizează chipul artistului, îl ridică la rang de generalitate, de cunoaştere a adevărurilor primordiale. Predispus spre afirmarea propriei identităţi creatoare, eroul lui G. Meniuc este determinat de o „sfâş̧iere” lăuntrică, de o răvăşire sufletească. Astfel, într-o poezie din anii 80 , autorul îşi revendică trăirile printr-o ambiguitate simbolică, iar dispariţia iubitei este redată prin intermediul unor acorduri elegiace venite prin vocabula folclorică:

„Tu erai demult plecată în lume,

Grierii amuţiră şi ei în grădină, 
În solitudinea nopţii vedeam cum răsai,

Din iarbă, din aer, din valuri.”

\section{(Toamna lui Orfeu)}

Regăsirea interioară are loc prin chemarea amintirii, care anihilează sentimentul despărţirii, orientând personajul liric spre redimensionarea artistică a trăirilor şi aspiraţiilor sufleteşti „spre elegia singurătăţii sale fără leac” (Meniuc, 2010, p. 19), unde:

„Pierdute dalbe salbe, brăţări ca să le poarte

Frumoasa mea din Deltă, în luntre de pescar

Fiorul lor ca roua s-a scuturat departe

La cercănaş de lună, la bouri de hotare."

(Cântec de dor)

Este, de fapt, o meditaţie despre curgerea dureroasă a timpului şi statornicia sentimentelor umane, despre permanentizarea valorilor general-umane. Acordurile elegiace şi sentimentul mistuitor al iubirii imprimă poeziei un aer demonic, o reverie eminesciană. Versul lui G. Meniuc, despovărat de finalitate, devine în cele din urmă „o stare de sine şi în sine”, pentru a exprima ideea de regăsire sufletească, de sfidare a convenţiilor existenţiale impuse de realitatea durută. Invocarea iubitei pierdute într-un spaţiu atemporal are loc printr-o dimensiune mitică, acolo unde viaţa şi moartea, dragostea şi suferința, amurgul şi lumina, se condiţionează reciproc.

G. Meniuc îşi revendică trăirile, stările sufleteşti în conformitate cu o viziune artistică arhetipală, iar vibraţiile folclorice vor deveni, în acelaşi timp, şi o modalitate de comunicare erotică. Or, aşa cum ne sugerează scriitorul în paginile sale de corespondență către T. Găluşcă, ,frumoasa... din Deltă, în luntre de pescar” ,este o fărâmă din tine", cu alte cuvinte, este nenumită, dar omniprezenta şi „,neuitata iubită”, (2010, p. 143), pe care eroul liric o doreşte într-un moment de intensă efervescenţă lăuntrică şi o va regăsi anume prin intermediul sugestiei folclorice, dincolo de hotarele veşniciei. Or, ,această mare iubire, după cum scrie în altă parte G. Meniuc, a lăsat o urmă adâncă în creaţia mea..." (Meniuc, 2010, p. 99), iar „curăţenia ta sufletească, cuvintele tale calde, luminoase, pline de viaţă m-au însufleţit în existenţa mea tristă...”, aşa cum ,... suflul viu al creaţiei populare ... mi-a fost foarte necesar" (Meniuc, 2010, p. 99).

La rândul ei, T. Găluşcă îşi exteriorizează gândurile prin nişte mărturisiri pline de tandreţe, gingăşie, dar şi printr-o evidentă profunzime a sentimentului trăit, rar întâlnit în literatura noastră. Trăirile nuanţate, vibraţiile sufleteşti copleşesc prin intensitate şi parcă sunt smulse din adâncurile simţirii populare, ele redau „Zvârcolirea sufletească a omului” (Rusu, 1967, p. 32) şi nostalgica lui îngândurare în fața trecerii ireversibile. Aceste „clipe sfinte” se profilează aidoma unui zbor prelung de pasăre, ,din mâinile tale zboară o pasăre nemaivăzută” (Meniuc, 2010, 
p. 99), scrie G. Meniuc, ca să scruteze depărtările, să ne aducă la „ora risipită-n veşnicii”, pentru ca dincolo de ea să răsune dureros de viu nişte confesiuni tulburătoare, încadrate în tendinţa de exteriorizare a unui „sentiment total, abisal, ireversibil, în stare de cele mai sublime momente de elevaţie”, dar şi de „catastrofele cele mai dureroase" (Fochi, 1988, p. 15), aşa cum vom sesiza în continuare din relatările ce urmează: „Prieten al frumosului, al profunzimilor limbii şi vieţii ce dai cuvintelor ca un meşter faur, cât te admir! Citesc şi recitesc şi mă minunez de ce poate elabora sufletul tău mare" (Meniuc, 2010, p. 187). Întrevedem o comuniune sufletească, ce este marcată de nişte dimensiuni atemporale, făcând abstracţie de convenţiile timpului istoric: „Noi nu ne vom întâlni, eu voi muri, dar vorbele noastre se vor întâlni ”, „,...se vor întâlni, hăt departe” (Meniuc, 2010, p. 98). Chiar dacă „Prutu ista ni disparti” (Găluşcă, Nicola, 1999, p. 202), aşa cum s-a întâmplat pe multpătimitul pământ al Basarabiei în răstimp de mai multe decenii, folclorul şi poezia le-a determinat existenţa printr-o stare de regăsire spirituală totală, întru contemplarea lăuntrică a esenţelor primordiale ale trecerii omului pe pământ. Or, dialogul G. Meniuc vs T. Găluşcă, colaborarea lor pe tărâmul creaţiei artistice a devenit un frumos exemplu de comunicare sufletească , ,o creangă de aur care va luci în sine, în afară de timp" (Sadoveanu, 1976, p. 191), menită să dăinuie dincolo de hotarele existenţei terestre.

\section{Referințe bibliografice:}

1. AF AŞM, 1968, ms. 178, f. 43, Frecăţei (Limanscoe), Reni - Odesa, inf. A. Bunulu, culeg. Gr. Botezatu.

2. BĂLĂET, Dumitru. Eterna regăsire. Craiova: Editura Cartea Românească, 1979.

3. BOMHER, Noemi. Mit şi mitologie eminesciană. Iaşi: Editura Virginia, 1994.

4. CIMPOI, Mihai. Prefaţă. În: George Meniuc. Interior cosmic. Chişinău: Editura Litera - Internaţional, 2004.

5. COMAN, Mihail. Bestiarul mitologic al românilor. Bucureşti: Editura Fundaţiei Culturale Române, 1996.

6. CESEREANU, Dumitru. Arghezi şi folclorul. Bucureşti: Editura pentru Literatură, 1966.

7. DOLGAN, Mihail. Metafora poetică şi semnificaţiile ei în poezia sovietică moldovenească. Chişinău: Editura Ştiinţa, 1974.

8. EVSEEV, Ivan. Dicţionar de simboluri şi arhetipuri literare. Timişoara: Editura Amarcand, 1999.

9. FERBER, Mikail. Dicţionar de simboluri literare. Chişinău: Editura Cartier, 2001.

10. FOCHI, Adrian. Valori ale culturii populare române. Bucureşti: Editura Minerva, 1988. 
11. GĂLUŞCĂ, Tatiana, NICOLA, Ioan. Folclor român din Basarabia. Chişinău: Î. E. P. Ştiinţa, 1999.

12. MENIUC, George. Pagini de corespondenţă. Ediţie îngrijită, studiu introductiv, note şi comentarii de Elena Ţau. Chişinău: Editura Grafema Libris, 2010.

13. RUSU, Liviu. Viziunea lumii în poezia noastră populară. Bucureşti: Editura pentru Literatură, 1967

14. SACA, Serafim. Aici şi acum: 33 confesiuni sau confesiuni de credinţă. Chişinău: Editura Literatura artistică, 1976.

15. TEODORESCU, Alexandru. Lucian Blaga şi cultura populară românească. Iaşi: Editura Junimea, 1983.

16. SADOVEANU, Mihail. Creanga de aur. Bucureti: Editura Minerva, 1976.

17. WALD, Hendri. Laicizarea miturilor. În: România literară, 1992, 12-18 august.

Notă: Articolul a fost realizat în cadrul proiectului de cercetare 20.80009.1606.03 Contexte socioculturale autohtone şi interconexiuni europene în creația populară şi literatura cultă din Basarabia (sec. XIX până în prezent), Institutul de Filologie Română „B. P.-Hasdeu” al MEC. 